\title{
National Health Service laboratories in England, 1966-74
}

\author{
M. A. BUTTOLPH \\ From the Department of Health and Social Security, London SE1 6TE, UK
}

SUMMARY Laboratory workloads increased substantially between 1966 and 1974, the total number of laboratories was reduced, and productivity improved. These trends are likely to continue, but in the present economic situation the availability of accommodation will be an important constraint in determining the pattern of future development.

The Department of Health and Social Security (DHSS) monitors the performance of the National Health Service (NHS) in England and, for this purpose, collects data from health authorities. Some of the data relating to laboratories for the period up to and including NHS reorganisation in 1974 have been analysed to reveal trends and to indicate changes which could take place in the future.

Accounts have been published of the development of individual laboratory disciplines such as clinical chemistry (Whitehead, 1971), and of the work and organisation of single laboratories or groups (Barnard, 1976; Rose and Abel-Smith, 1972). Some aspects of the laboratory service have been considered from a national point of view. Lathe and Mitchell (1966) described the staffing of NHS clinical chemistry laboratories, and Greenbury (1971) and Baron (1974) have made detailed studies of the medical manpower situation in laboratories. The most recent comprehensive description of the organisation of NHS laboratories is that given by Johnson (1969).

\section{Sources of data}

Laboratory workload data are submitted to DHSS each year on form SBH6. One form is completed for each laboratory that undertakes NHS work, covering the 12-month period to 31 December. The unit of workload measurement is the request, defined as 'a demand in respect of one patient for pathology work in one division of the laboratory. Thus a demand for

\footnotetext{
${ }^{1}$ Present address: University of London, Senate House, London WC1E 7HU, UK.

Received for publication 25 May 1977.
}

investigations in haematology and chemical pathology will count as two requests (one under each category)'.

In order to normalise the workload data, a weighting factor is applied to the numbers of requests received in each discipline. These factors are intended to reflect differences in the amount of time needed to deal with requests in different disciplines (Ministry of Health, 1964). The values of the weighting factors are given in Table 2. This method of workload measurement can be relied upon to reveal only general trends. Although simple to use, it has been criticised as being insensitive and unreliable; the introduction of a new system of workload measurement is under consideration. In what follows, workloads in individual disciplines are expressed in terms of numbers of requests, the weighted request being used only as a measure of the workload of two or more disciplines taken together.

The form SBH6 records the number of requests in each main discipline (listed in Table 4) received from various sources, that is, main hospital using laboratory, other hospitals, general practitioners, Public Health Laboratory Service, and other sources. In addition, the form records the numbers of pregnancy tests and of postmortem examinations carried out. In some cases, no workload data could be obtained for laboratories which were active in 1974. These deficiencies were compensated by using data from the same hospitals for 1973 or for 1975-see note 1 of Table 1. In smaller numbers of cases, reporting deficiencies in years before 1974 have been compensated by using earlier data. The errors introduced in this way are very small.

It should be borne in mind that these data refer to the analytical services provided by laboratories and 
Table 1 Changes in numbers of laboratories, workloads, and numbers of medical laboratory technicians, $1966-74$

\begin{tabular}{|c|c|c|c|c|c|c|}
\hline & 1966 & 1968 & 1970 & 1972 & 1974 & $\begin{array}{l}\% \text { Change } \\
1966-74\end{array}$ \\
\hline Number of laboratories & 641 & 619 & 586 & 537 & 500 & $-22 \cdot 0$ \\
\hline Total requests (millions) & $29 \cdot 46$ & $33 \cdot 85$ & $39 \cdot 42$ & $44 \cdot 90$ & $50 \cdot 49^{1}$ & -71.4 \\
\hline Total weighted requests (millions) & $83 \cdot 47$ & 96.45 & $113 \cdot 12$ & $129 \cdot 75$ & $146 \cdot 70^{1}$ & $+75 \cdot 7$ \\
\hline Total medical laboratory technicians (MLTs) & 7557 & 8312 & 9382 & 10435 & $11486^{2}$ & $-52 \cdot 0$ \\
\hline Mean weighted requests per lab. & 130000 & 156000 & 193000 & 242000 & 293000 & $\cdots 125$ \\
\hline Mean MLTs per lab. & $11 \cdot 8$ & $13 \cdot 4$ & $16 \cdot 1$ & $19 \cdot 4$ & $23 \cdot 0$ & $\because 94.9$ \\
\hline Mean weighted requests per MLT & 11045 & 11604 & 12057 & 12433 & 12772 & -15.6 \\
\hline
\end{tabular}

Notes:

1 Data on the workloads of some laboratories were not available for 1974. These deficiencies were compensated by using data for 1973 (five laboratories) or 1975 (one laboratory). The total workload of these six laboratories in 1973 or 1975 (as appropriate) was 1.6 million weighted requests, $1 \%$ of the total, so that the error introduced by this approximation is substantially less than $1 \%$.

2 One Region was unable to give the number of MLTs in post on 30 September 1974. An estimate was made from the total workload of the Region, assuming that the workload (weighted requests) per MLT was the same in that Region as in the country as a whole (as it had been in 1973). The error introduced by this approximation was not more than $1 \%$ of the total.

do not take account of the work involved in other activities such as teaching, research, and consultation.

DHSS also collects data on the number of medical laboratory technicians (whole-time equivalents) in post on 30 September each year. One Regional Health Authority was unable to give an accurate figure for 1974; an estimated value, calculated as described in note 2 of Table 1, has been used.

\section{Numbers of laboratories}

In 1966, returns were received for 641 laboratories; by 1974 the number had fallen by $22 \%$ to 500 (Table 1). About $8 \%$ of hospitals were themselves closed, but most of these did not include a laboratory. Thus in most cases in which a laboratory was closed, the associated hospital continued to function, sending its laboratory work to another centre. The centralisation of laboratory work is further discussed below.

The percentage reductions in the numbers of laboratories carrying out work in bacteriology, clinical chemistry, and haematology were closely similar $(27 \%-28 \%)$, although the absolute numbers were different (Table 2). There was also a substantial reduction (almost $25 \%$ ) in the number of hospitals at which postmortem examinations were made. The numbers of centres providing services in venereal disease serology, histology, and cytology also fell, but by lesser proportions $(9 \%-18 \%)$.

\section{Laboratory size}

Figure 1 shows the distributions of laboratories according to workload in 1966 and 1974. During this period the number of small laboratories decreased and the number of large laboratories increased. To some extent this is a reflection of the general upward

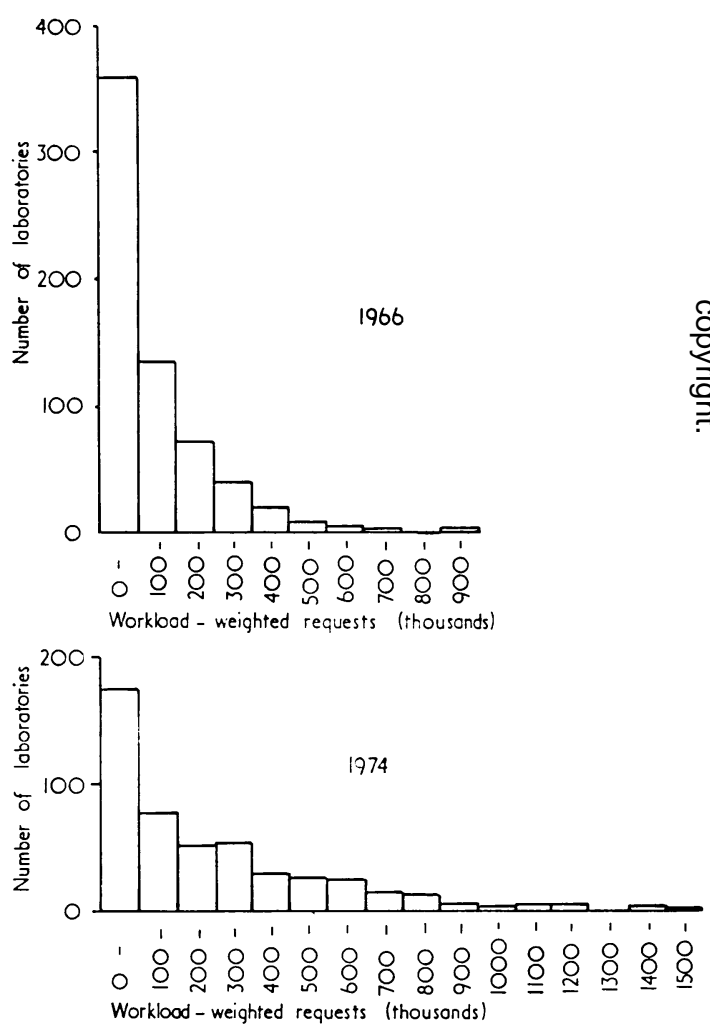

Fig. 1 Distributions of laboratories according to workload, 1966 and 1974.

trend of workloads, but if this effect is eliminated, it can be shown that a disproportionate number of small laboratories were among those closed.

Allowance is made for the general trend in workloads by defining laboratory size in terms of the notional population served. In 1970 DHSS advised 
Table 2 Changes in numbers of laboratories, postmortem rooms, and workloads, 1966-74

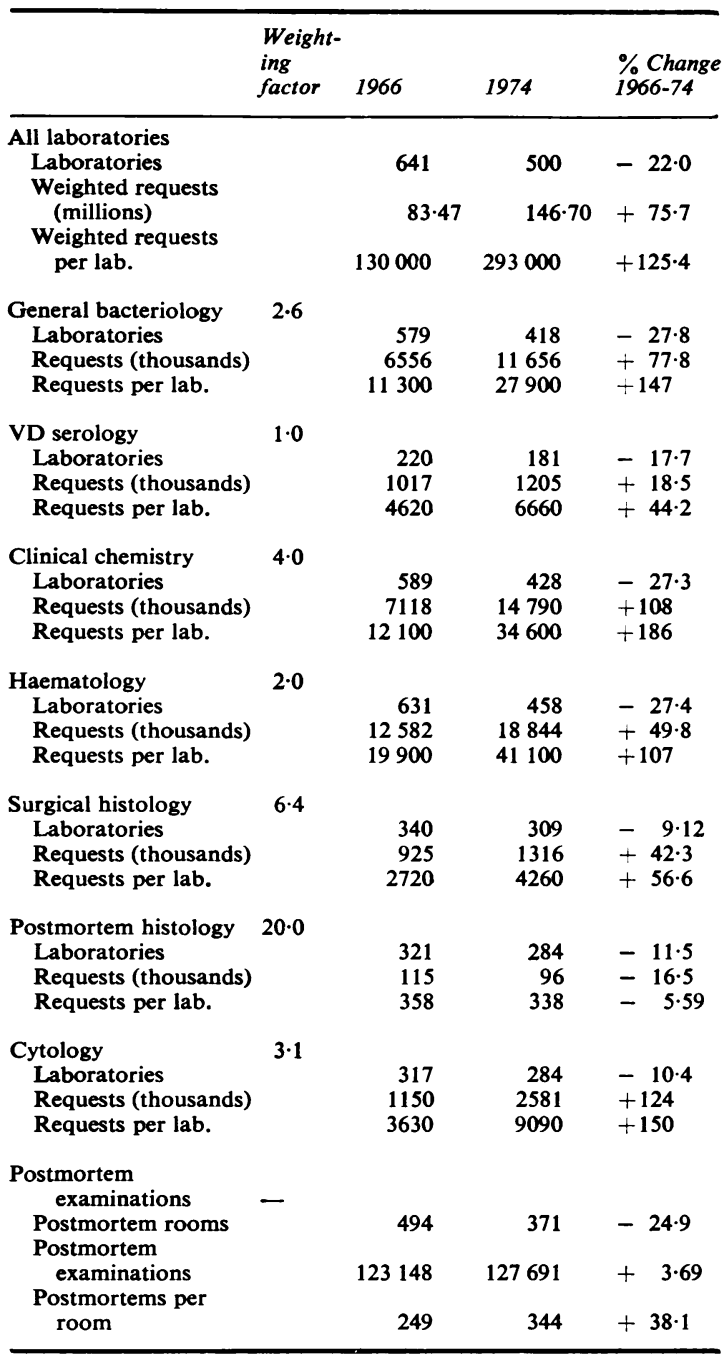

hospital authorities to attempt to create 'area laboratories' serving a population of 200000 or more. (The use of the term 'area' in this context antedates the reorganisation of the NHS in 1974, in which England was divided into 90 Health Areas with populations substantially greater than 200000 .) The provision of a service to a population of 200000 or more is here taken to define a 'large' laboratory. A notional population served of 27500 or less is taken (arbitrarily) to define a 'small' laboratory.

As shown in Table 3, when the effect of the general upward trend of workloads is eliminated, we find that $43 \%$ of small laboratories were closed between 1966 and 1974 . In the same period, $22 \%$ of all laboratories were closed, and there was a substantial increase $(44 \%)$ in the number of large laboratories. The centralisation of services was achieved in the main by closing smaller laboratories, the work which had been carried out by them being transferred to larger units.

Table 3 Numbers of small and large laboratories in 1966 and 1974

\begin{tabular}{llllll}
\hline & $\begin{array}{l}\text { Small laboratories } \\
\text { (Serving a notional } \\
\text { population of 27 500 } \\
\text { or less) }\end{array}$ & $\begin{array}{l}\text { Large laboratories } \\
\text { (Serving a notional } \\
\text { population of 200 000 } \\
\text { or more) }\end{array}$ \\
\hline $\begin{array}{lllll}\text { Workload (thousands } \\
\text { of weighted requests) }\end{array}$ & $\leqslant 50$ & 1974 & & 1966 & 1974 \\
$\begin{array}{c}\text { Number of labs in } \\
\text { size range }\end{array}$ & 256 & 147 & & 48 & 696 \\
$\begin{array}{c}\text { Change in number of } \\
\text { labs in size range }\end{array}$ & $-43 \%$ & & & & $+44 \%$ \\
\hline
\end{tabular}

\section{Changes in workload}

In the eight years following 1966, there were exponential increases in the total number of requests and in the numbers of requests received in each of haematology, clinical chemistry, and bacteriology (Fig. 2). There is an indication that the rates of increase of these indices were less in 1974 than in earlier years.

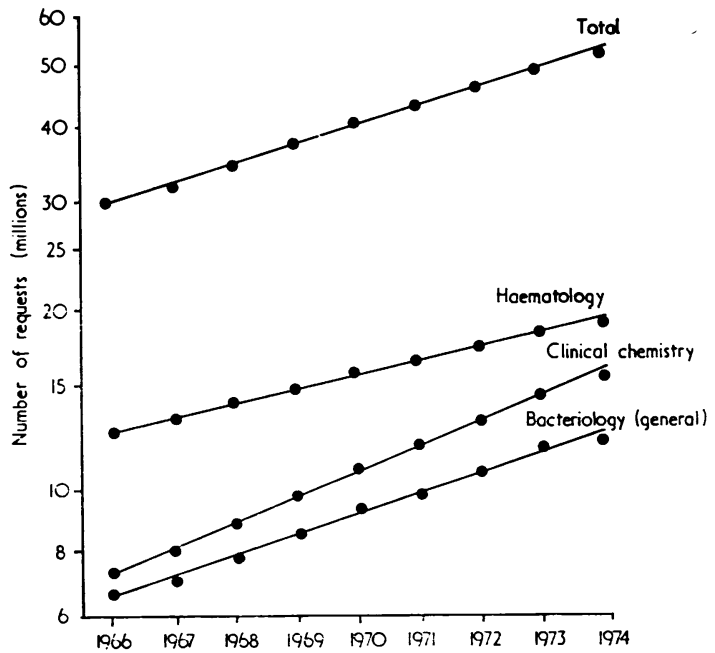

Fig. 2 Changes in total workload, and in workloads in haematology, clinical chemistry, and general bacteriology. 
As shown in Fig. 3, the total numbers of requests in cytology and in surgical histology increased linearly with time between 1966 and 1974. The reasons why workloads have increased exponentially in some subjects and linearly in others are considered later (see discussion). For both surgical histology and cytology there is also an indication that the increase in workload in 1974 was less than in earlier years.

The amount of postmortem histology carried out declined slightly over the period, while the number of necropsies (not shown) remained virtually constant at $123500 \pm 4500$. The mean number of postmortem histology requests per necropsy declined from 0.93 in 1966 to 0.75 in 1974 . A relative decline in interest in postmortem work has been observed in other countries; the situation has been reviewed by Rippey and Chatgidakis (1975).

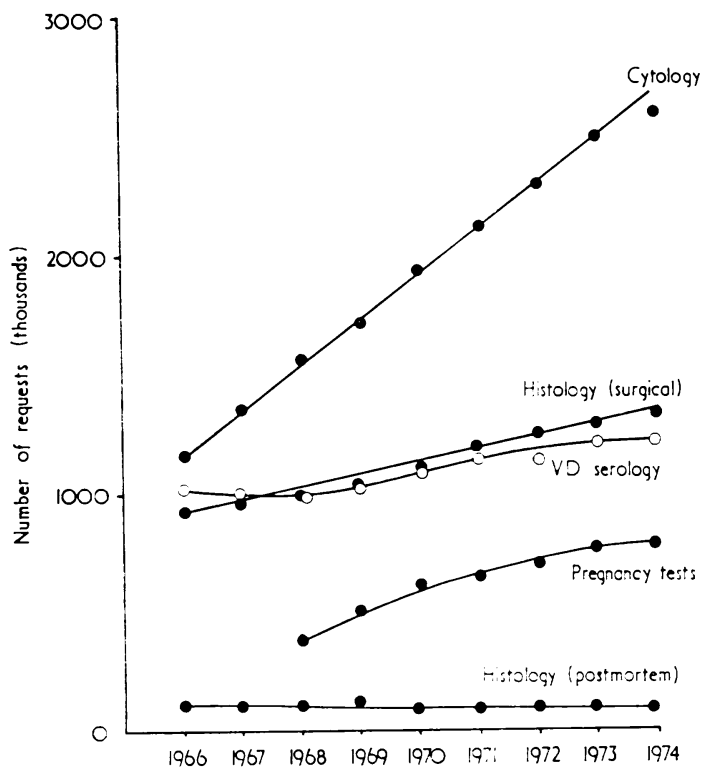

Fig. 3 Changes in workloads in cytology, histology, $V D$ serology, and pregnancy testing.

The number of pregnancy tests carried out in hospital laboratories appears to be approaching a steady value of about 800000 per annum. In 1971, Brodie and Porter predicted that in 1972 the number of pregnancy tests carried out at Aberdeen City Hospital would exceed the number of births among the population served. This change in relativity did in fact occur in England in 1972; in that and subsequent years the number of pregnancy tests exceeded the number of live births. Although some correlation might be expected between these two quantities, there is no prima facie reason why it should take the form of an equality. Furthermore, the true number of pregnancy tests carried out in England is unknown, because significant numbers (not included in the data presented here) are performed in the surgeries of general practitioners and in private laboratories.

Different rates of workload increase in the various disciplines result in changes in the distribution of work. For example, the workload in clinical chemistry has increased by an average of $10 \%$ per annum (doubling in seven years), whereas haematology work has increased at a rate of $5 \%$ per annum (doubling in 14 years). In 1966, $24 \%$ of all requests were for work in clinical chemistry, but the proportion had risen to $29 \%$ in 1974 . The corresponding figures for haematology were $43 \%$ and $37 \%$ respectively (Table 4).

A crude estimate of the proportion of effort devoted to each field of work can be obtained from the percentage of weighted requests in each discipline. As measured on this basis, almost two-thirds of the total national effort was devoted to clinical chemistry and haematology in both 1966 and 1974

\section{Sources of requests}

The clinical laboratory is traditionally part of the $\overrightarrow{0}$ hospital which it serves. However, an increasing amount of work is received from sources other that the main hospital served. In 1966, these other sourceg submitted $31 \%$ of all requests, a proportion which had risen to $38 \%$ by 1974 . The important factors in this trend were requests from other hospitals and from general practitioners. If the trend continues, in 10 years' time the average laboratory will receive less than half of its workload from the hospital to which it is attached.

As discussed earlier, many small laboratories have been closed and their workloads transferred to other centres. In the data reported for the laboratories remaining, this transferred work appears in the category 'requests received from other hospitals' (see 8 'Sources of data'). In 1974, 10.19 million requests were received from 'other hospitals'. This represented 0 $20.2 \%$ of the total workload, a proportion which has declined slightly from the highest value reached $(20.8 \%)$ in 1971 . It appears that the rate at which centralisation of services was being accomplished o reached a maximum value in 1971 and remained $N$ virtually constant in the succeeding three years.

There has been a substantial increase in the number of requests submitted by general practitioners-from 2.8 million in 1966 to 6.7 million in 1974. Furthermore, work from GPs represents an increasing proportion of the total. In 1966, requests from GPs constituted $9.7 \%$ of the national total; by 1974 the proportion had risen to $13.4 \%$. 
Table 4 Percentage distributions of workloads in main disciplines, 1966 and 1974

\begin{tabular}{|c|c|c|c|c|c|c|c|}
\hline & $\begin{array}{l}\text { General } \\
\text { bacteriology }\end{array}$ & $\begin{array}{l}V D \\
\text { serology }\end{array}$ & $\begin{array}{l}\text { Clinical } \\
\text { chemistry }\end{array}$ & Haematology & $\begin{array}{l}\text { Surgical } \\
\text { histology }\end{array}$ & $\begin{array}{l}\text { Postmortem } \\
\text { histology }\end{array}$ & Cytology \\
\hline \multicolumn{8}{|l|}{ Requests } \\
\hline 1966 & 22 & 3 & 24 & 43 & 3 & 0.4 & 4 \\
\hline 1974 & 23 & 2 & 29 & 37 & 3 & 0.2 & 5 \\
\hline \multicolumn{8}{|c|}{ Weighted requests } \\
\hline 1966 & 20 & 1 & 34 & 30 & 7 & 3 & 4 \\
\hline 1974 & 21 & i & 40 & 26 & 6 & 1 & 5 \\
\hline
\end{tabular}

In 1966 , most requests from GPs $(54 \%)$ were for work in haematology; by 1974 this had fallen to $41 \%$. The demand for work in bacteriology and clinical chemistry rose during this period to $28 \%$ and $18 \%$ respectively of all requests from GPs.

\section{Medical laboratory technicians}

Although there was an increase in the number of medical laboratory technicians (MLT) employed in the period under study, as a percentage this was less than the increase in workload (Table 1). The mean number of weighted requests per MLT ( a crude measure of productivity) increased by $15.6 \%$.

Data on the number of MLTs employed in individual disciplines were not collected centrally before 1974. Thus it is not possible readily to assess productivity changes in different fields of work on a national basis. Whitby (1967) reported a substantial increase in productivity (tests per MLT) in the clinical chemistry laboratories of Edinburgh Royal Infirmary. For example, between 1960 and 1966, productivity increased by more than $100 \%$. The use of 'tests' rather than 'requests' to express workload gives a rather higher value for the productivity increase since there has been a general increase in the number of tests carried out to meet each request. However, it is clear that the introduction of automatic analysers for clinical chemistry in the early 1960s made possible substantial increases in productivity. The introduction at that time of new instruments for haematology also led to improved productivity (Nelson and Lamont, 1961).

Automation has had less impact in other disciplines, so that one would not expect the productivity of laboratories as a whole to have increased at such high rates. Furthermore, the effects of automation were greatest when it was first introduced in the early $1960 \mathrm{~s}$, so that a lesser increase in productivity would be expected in later years, in spite of the introduction of increasingly labour-efficient systems.

\section{Discussion}

Two major trends emerge from the data presentedthe increase in workloads and the changing structure of the laboratory service. Although the two are closely interrelated, it is convenient to consider each trend separately.

Although it has come to be accepted, the growth in laboratory workloads is remarkable. In both 1973 and 1974, the numbers of requests received by hospital laboratories in England exceeded the total population served. Other authors have also observed exponential increases in laboratory workloads (Rose and Abel-Smith, 1972; Whitby, 1967) but the reasons for this effect are not clear. It may be that it results from a combination of two types of growthan increasing demand for each type of test, and an increase in the variety of tests available. In this context the actual introduction of a new test which had earlier been available only in research centres has only a small effect. But the effective availability of tests increases as technical improvements make them easier to perform. As a test becomes better established, more laboratories will be able to accept requests for it, and it will be requested with increasing frequency as clinicians acquire a better appreciation of the significance of its results.

If this explanation is correct, the introduction of new tests has been an essential element in the exponential growth of clinical chemistry, haematology, and microbiology. Work in these three fields accounted for $89 \%$ of all requests in both 1966 and 1974 (Table 4), so that total laboratory workload also increased exponentially.

Workloads in cytology and in surgical histology increased linearly with time (Fig. 3). The work of the cytology department consists largely of a single procedure, screening for early signs of cancer of the uterine cervix. Many cytology departments aljo examine specimens from other sites, such as the lungs or the bladder, but in national terms these represent only a small proportion of the total 
number of requests. For example, Oswald et al. (1975) found that in 1971 cytology departments in England examined 140000 sputum specimens, which was in that year less than $7 \%$ of the total number of requests. The growth of workload in cytology resulted largely from an increasing demand for a single procedure, so that the mechanism suggested above to explain exponential increases in the workloads in other disciplines does not apply in this case.

The situation in surgical histology is more complicated, but it may be that in this field also the growth in workload has been due largely to an increased demand for a fixed number of tests.

For planning purposes, it is necessary to assess how workloads are likely to change in the future. There are signs that the increase in workload in 1974 was less than in preceding years, but in that year external factors combined to reduce demand and the capacity of laboratories to meet it: several groups of workers in the NHS took industrial action, which resulted in a general reduction in the level of activity in hospitals; laboratories themselves encountered some difficulties in obtaining supplies; and the NHS as a whole was reorganised for the first time since its inception.

These unusual factors are probably sufficient to explain the lower rate of workload increase in 1974, and it would be unwise to conclude that the trend has changed from what is effectively a single observation. A change to a lower rate of increase was reported on an earlier occasion (Association of Clinical Pathologists, 1968) but proved to be false. Barnard (1976) has predicted that workloads will continue to grow exponentially until the end of the century.

The present adverse economic situation has resulted in the NHS building programme being curtailed. The effects of this restriction are likely to be felt for some years and must be taken into account when considering the way in which the laboratory service is likely to develop.

The availability of accommodation will be an important factor in determining whether or not laboratories can meet substantial increases in demand in the future. Although a part of any increase in workload can probably be absorbed, as in the past, by improved productivity, it will be necessary to employ more staff. As shown in Table 1, between 1966 and 1974 increasing numbers of technical staff were concentrated into fewer laboratories; the mean number of MLTs per laboratory almost doubled.

Increasing workloads (and hence increasing staff numbers) could be accommodated by expansion in the only other dimension available-time. For many years the cost-benefit equation has been altering in favour of the extended working day, and this expedient will have to be considered seriously in the future.

The second major trend, the changing structure of the laboratory service, reflects attempts at rationalisation, that is, the development of a well-organised service with working units of optimum size. The NHS was not established as an integrated whole but was constructed from the facilities available at its inception 30 years ago. Considerable progress has been made towards rationalisation, but much remains to be done. It is also necessary to alter the structure of the laboratory service to accommodate changing patterns of demand.

Between 1966 and 1974 there was a reduction of $22 \%$ in the total number of laboratories (Table 2). During that period health authorities pursued a policy of workload centralisation, that is, the closure of some laboratories, the work from the sources served by them being transferred to other centres.

As described earlier, the laboratories closed have been predominantly those with smaller workloads, presumably because they are identified as using resources relatively inefficiently. Interlaborators survey schemes in clinical chemistry (Whitehead $e$ al., 1973) and haematology (Lewis, 1975, personat communication) have shown that smaller laboratories tend to produce less accurate results.

The closure of smaller laboratories has made an important contribution to the development of a more efficient service, but it brings diminishing returns as the number of small laboratories declines. The rate of workload centralisation reached a maximum value in 1971 and declined thereafter. The policy of centralisation is likely to make a diminishing contribution to the development of the service; a major building programme to replace and relocate laboratory accommodation can be regarded only as a long-term solution.

Further rationalisation could be achieved by the adoption of new forms of laboratory organisation. In 1970, Goldberg and Mitchell proposed that the service in clinical chemistry should be provided by a group of specialised units serving a population of 500000 to 700000 . The discipline would be divided into eight or more branches such as enzymology, toxicology, and automation, and work in one or more of these would be centralised at each of the existing laboratories in the area served. An important feature of this proposal is that the service could be established in the accommodation already available.

Mills and Dawson (1976) have recently described an integrated clinical chemistry service organised in this way, and it is possible to devise similar arrange- 
ments for other disciplines. In this way the process of rationalisation could be continued with a minimum of capital expenditure.

Until recently I was a member of the scientific staff of the Department of Health and Social Security's Medical Division. The statistical information in this paper is Crown Copyright and is reproduced with the permission of Her Majesty's Stationery Office. The opinions expressed are mine alone and are not attributable to any other person in the DHSS.

\section{References}

Association of Clinical Pathologists. (1968). Data processing in clinical pathology. Journal of Clinical Pathology, 21, 231-301.

Barnard, H. F. (1976). Growth of medical laboratory work during 1920-2000. British Medical Journal, 1, 383-384.

Baron, D. N. (1974). Training and career appointments in the pathological sciences in the United Kingdom. Journal of Clinical Pathology, 27, 1013-1014.

Brodie, J., and Porter, I. A. (1971). Pregnancy testing (Letter). British Medical Journal, 4, 489.

Department of Health and Social Security (1970). Hospital Laboratory Services. HM (70) 50.

Goldberg, I. J. L., and Mitchell, F. L. (1970). Clinical biochemistry in the hospital laboratory services. Lancet, 2, 1240-1243.
Greenbury, C. L. (1971). Manpower in pathology 19691975. Journal of Clinical Pathology, 24, 551-563.

Johnson, A. P. (1969). Organisation and Management of Hospital Laboratories. Butterworths, London.

Lathe, G. H., and Mitchell, F. L. (1966). Staffing of clinical biochemistry laboratories serving the National Health Service. Lancet, 1, 1413-1415.

Mills, R. J., and Dawson, J. (1976). Centralisation of pathology laboratories. In Scientific Aids in Hospital Diagnosis, edited by J. P. Nicholson. Pergamon Press, Oxford.

Ministry of Health. (1964). Revision of Pathology Statistics. HM (64) 82.

Nelson, M. G., and Lamont, A. (1961). Haemoglobinometry by an automatic analytical procedure. Journal of Clinical Pathology, 14, 448-450.

Oswald, N. C., Hinson, K. F. W., Canti, G., Husain, O. A. N., Girling, D. J., Tall, R., Stephens, R. J., and Fox, W. (1975). Survey of the Sputum Cytology Service in England and Wales. Thorax, 30, 489-496.

Rippey, J. J., and Chatgidakis, C. J. (1975). The role of the autopsy in modern medical practice. South African Medical Journal, 49, 662-664.

Rose, H., and Abel-Smith, B. (1972). Doctors, Patients and Pathology. Bell, London

Whitby, L. G. (1967). Automation in clinical chemistry. Hospital (Lond.), 63, 89-94.

Whitehead, T. P. (1971). A view from a bridge. Annals of Clinical Biochemistry, 8, 1-7.

Whitehead, T. P., Browning, D. M., and Gregory, A. (1973). A comparative survey of the results of analyses of blood serum in clinical chemistry laboratories in the United Kingdom. Journal of Clinical Pathology, 26, 435-445. 